\title{
Unusual Presentation of Foreign Body in Sigmoid Colon Simulating Acute Appendicitis-Chance Detection on OT table
}

\author{
AmalPrakashPatra*,Dr YousufPerwez**,Dr Sridhar Pradhan***, \\ Dr SaurabhBokade\# \\ *Specialist, Department of Surgery, Tata Main Hospital, Jamshedpur
}

\begin{abstract}
Foreign body impacted in the rectum is a common clinical presentation but one in the sigmoid colon having migrated from rectum is not so common. We report a case of 12 year old boy who presented with abdominal pain in the right lower quadrant and irregular bowel habit for 6 months. $X$ ray done on admission did not reveal any significant abnormality except a radio opaque linear shadow probably an artefact. Clinically it appeared to be acute appendicitis. On exploring the abdomen via McBurneys incision, a firm to hard lump was discovered in the RIF with dense adhesions. Progressive dissection of the lump revealed this to be an inflammatory sigmoid colon where as caecum and appendix appearing normal. Further exploration of the sigmoid colon lump revealed a palpable cylindrical foreign body. It appeared to be a commonly used ball pen possibly causing a micro perforation which got sealed and resulted in the lump. Sigmoid enterotomy was done and a ball point pen without cap was removed. Sharp end of the pen was found impinging on the inner wall of the colon. On table skiagram did not reveal any left over part of the pen. Postoperative period had progressive recovery and he was discharged on 5th postoperative day. These foreign bodies sometimes pose a diagnostic challenge to the surgeon because of concealment of the fact and delay in presentation.
\end{abstract}

Keywords: Appendicitis, Sigmoidcolon, foreign body, enterotomy

\section{Introduction}

Foreign bodies in the colon are rare clinical presentation ${ }^{[1]}$ In the absence of proper history by the patient they may remain unrecognised for long unless they produce acute symptoms. History of perversion may also be not forthcoming. These foreign bodies may present without any symptoms as an incidental discovery during investigation for other indication ${ }^{[2]}$. They may present with pain, gastrointestinal bleeding or bowel obstruction $^{[2,3]}$. Rarely can it present as a pelvic abscess. A 12 year old school going boy presenting with features suggestive of acute appendicitis is unheard of.

\section{Case Report}

A 12 year old boy was admitted with right lower quadrant pain since 6 months with increased in intensity for the preceding 4 days. Abdominal $\mathrm{X}$ ray shows an insignificant radiopaque shadow in the region of RT lower quadrant which was considered an artefact. Abdominal examination revealed signs of acute appendicitis. Decided for an emergency appendectomy.

Abdomen explored via McBurney`s incision and this revealed afirm to hard lump inthe right iliac fossa with dense adhesions around including the peritoneum. Progressive dissection showed the lump to be associated with sigmoid colon and inflammatory in nature. On further exploration a long tubular (cylindrical) foreign body was palpated in the sigmoid colon. Sigmoid enterotomy was done to remove a whole lengthof ball point pen without its cap in the lumen of sigmoidcolon[Figure1].

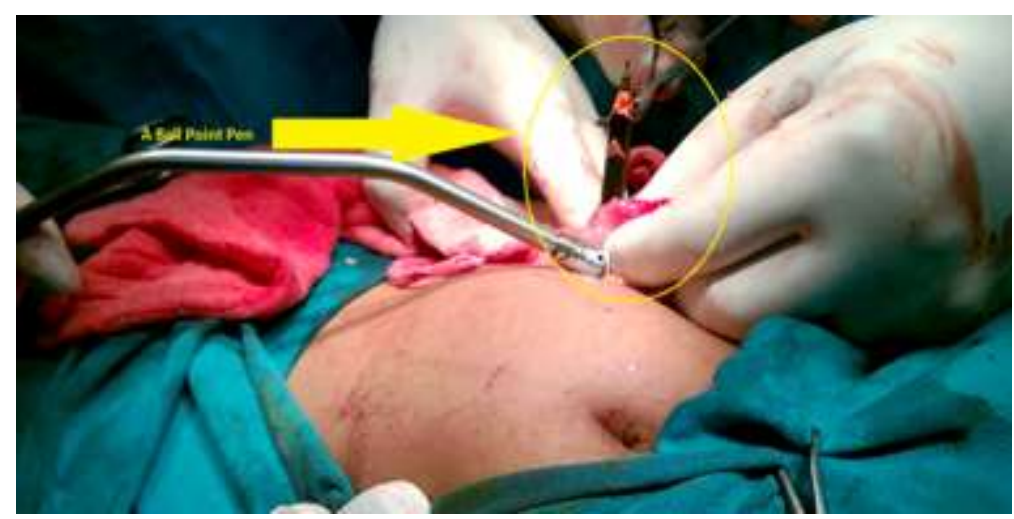

Fig 1: Foreign body in the process of retrieval through enterotomy wound 
Subsequent history of perverse behaviour confirmed the rectal insertion of the foreign body at school. Counsellingsession done by psychiatrist before discharge.

\section{Discussion}

This is an unusual case of foreign body,a whole length of ball point pen inserted through rectum as perverse behaviour in a young child of school going age. Rectal insertion of foreign body is notso common among paediatricagegroup ${ }^{[4]}$. The passage of foreign body depends on the anatomic conditions of gastrointestinal tracts. The presenting features vary according to the site of lodgement of foreign body and include features suggestive of appendicitis, pelvic abscesses, perforations, intussusceptions, irritable bowel syndrome, bleeding per rectum, etc. ${ }^{[5,67]}$. All sigmoid foreign bodies require surgical removal. However this child had chronic symptoms for six months either due to lack of perforation or obstruction. Moreover his symptoms mimicked acute appendicitis and were initially managed on the lines of acute appendicitis by many clinicians. There was concealment of the fact also regarding this behavioural incidence. The abdominal pain was explained by the increased bowel peristalsis or microscopic perforation getting sealed spontaneously around the lodged pen.

The value of imaging studies for a foreign body seems to be questionable in this case. Plain abdominalx ray could identify only the tip of the pen visualised as a shadow and wasconsidered an artefact.The removal of foreign body was done through sigmoid enterotomy.

Proper clinical history and examination will go a long way towards suspicion of such condition which presents in so many variable forms.

\section{References}

[1] Hellinger MD: Anorectal trauma and foreign bodies. Surg Clin North Am; 2002; 82: 1253-60.

[2] Goldberg JE, Steele SR: Rectal foreign bodies. Surg Clin North Am; 2010; 90: 173-84.

[3] Ruiz del Castillo J, Sellés Dechent R, Millán Scheiding M, Zumárraga Navas P, Asencio Arana F: Colorectal trauma caused by foreign bodies introduced during sexual activities: diagnosis and management.Rev Esp Enferm Dig; 2001; 93: 631-4.

[4] Ooi BS, Ho YH, Eu KW, Nyam D, Leong A, Seow-Choen F: Management of anorectal foreign bodies: a cause of obscure anal pain. Aust N Z J Surg; 1988; 68: 852-5.

[5] Koornstra JJ, Weersma RK: Management of rectal foreign bodies: Description of a new technique and clinical practice guidelines. World J Gastroenterol; 2008; 14: 4403-4406.

[6] Nehme Kingsley A, Abcarian H: Colorectal foreign bodies. Management update. Dis Colon Rectum; 1985; $28: 941$-4.

[7] Zezos P, Oikonomou A, Souftas V, Gkotsis D, Pitiakoudis M, Kouklakis G. Endoscopic removal of a toothpick perforating the sigmoid colon and causing chronic abdominal pain: a case report. Cases J. 2009;2:8469. 